\title{
Salvage hemostasis by scope compression during rectal endoscopic submucosal dissection
}

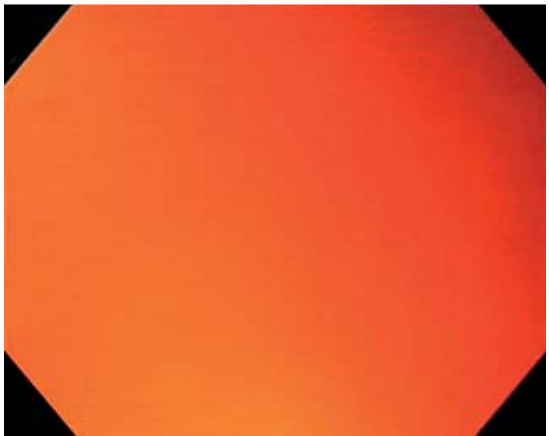

Fig. 1 During endoscopic submucosal dissection (ESD) of a large villous rectal lesion in a 65-year-old man, massive bleeding occurred despite continuous use of the washing pump.

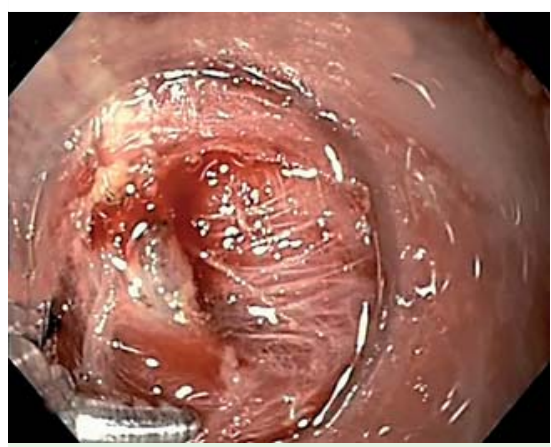

Fig. 4 Bleeding stopped after 5 minutes of compression with the cap.

A 65-year-old man was referred for endoscopic submucosal dissection (ESD) of a large villous rectal lesion (lateral spreading tumor, granular type). Massive bleeding occurred during the procedure. A washing pump on the accessory channel of the scope was used to locate the source of the bleeding, however bleeding obscured the entire field of the procedure despite continuous use of the washing pump ( $\bullet$ Fig. 1). After 1 minute of intense bleeding with washing, a spurting arterial bleeding was noted ( $\boldsymbol{O}$ Fig. 2). Adrenaline injection was ineffective. Clips were inappropriate because they would interfere with the procedure preventing its completion, and it was impossible to use coagulation forceps because of the high rate of bleeding, which prevented precise visualization of the source of the bleeding. Compression with the distal cap attached to the head of the endoscope resulted in

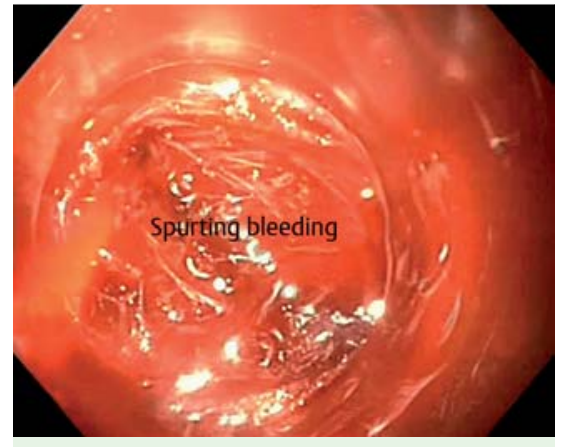

Fig. 2 Identification of spurting arterial bleeding after 1 minute of intense bleeding with washing.

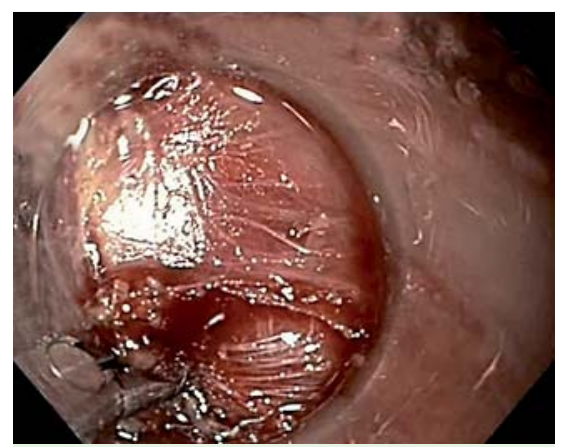

Fig. 5 Partial coagulation of the responsible vessel with hemostatic forceps.

an initial decrease in the bleeding after 1 minute of compression ( $\mathbf{~ F i g . 3 ) ~ a n d ~ s u b - ~}$ sequently stopped it after 5 minutes of compression ( $\bullet$ Fig.4) allowing partial coagulation of the artery responsible ( $\bullet$ Fig. 5). Then, before cutting it, the upstream part of the vessel was coagulated $(\bullet$ Fig. 6, $\odot$ Video 1). Finally, the ESD was completed. Pathology revealed a tubulovillous adenoma with in situ carcinoma with R0 margin.

Endoscopic submucosal dissection is the interventional endoscopic procedure with the greatest risk of bleeding. In ESD, hemostasis is considered part of the endoscopic therapy and not an adverse

\section{Video 1}

Salvage hemostasis by scope compression during rectal endoscopic submucosal dissection.

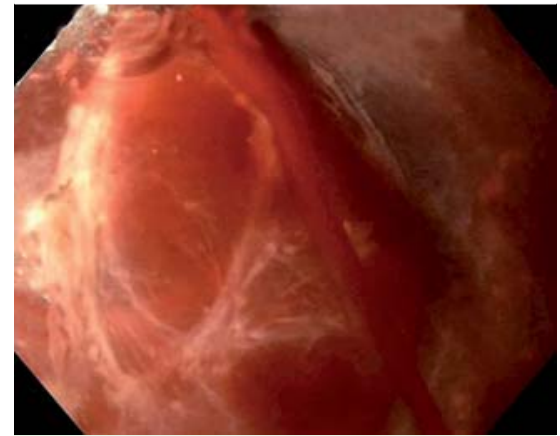

Fig.3 Initial decrease in the bleeding after 1 minute of compression with the distal cap attached to the head of the endoscope.

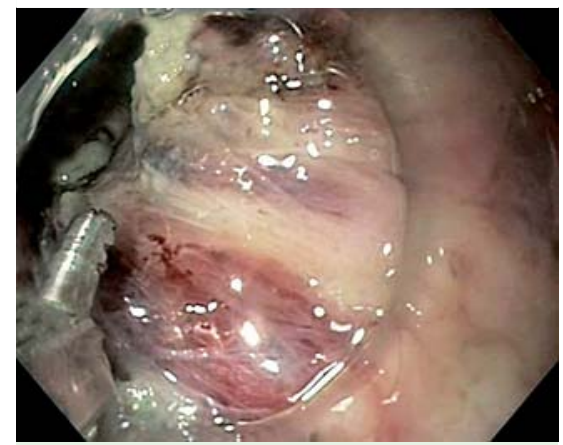

Fig. 6 Coagulation of the upstream part of the vessel with the coagulation forceps before cutting it.

event. During the procedure, prophylactic coagulation is necessary using dissection knives or hemostatic forceps [1]. Oozing bleeding can usually be managed with a knife, while arterial bleeding requires hemostatic forceps [2]. Uncontrolled bleeding is problematic because clips are the most effective means of treatment, but can interfere with the ESD procedure, preventing its completion. For a rectal location, mechanical compression with a distal cap or a finger [3] is a useful alternative before attempting more radical treatment with coagulation forceps.

\section{Endoscopy_UCTN_Code_CPL_1AJ_2AD}

\section{Competing interests: None}


Jérémie Jacques ${ }^{1}$, Romain Legros ${ }^{1}$, Paul Carrier ${ }^{1}$, Laura Mesturoux ${ }^{2}$, Sophie Geyl' ${ }^{1}$, Veronique LoustaudRatti $^{1}$, Denis Sautereau ${ }^{1}$

1 Service d'Hépato-gastro-entérologie, CHU Dupuytren, Limoges, France 2 Service d'Anatomopathologie, CHU Dupuytren, Limoges, France

\section{References}

1 Jacques J, Legros $R$, Chaussade $S$ et al. Endoscopic haemostasis: An overview of procedures and clinical scenarios. Dig Liver Dis 2014, Jul 9 [Epub ahead of print]

2 Hotta K, Yamaguchi Y, Saito Y et al. Current opinions for endoscopic submucosal dissection for colorectal tumors from our experiences: indications, technical aspects and complications. Dig Endosc 2012; 24: $110-$ 116

3 Neumann H, Wilcox CM, Mönkemüller $K$. Mechanical hemostasis by using the index finger during rectal endoscopic submucosal dissection. Gastrointest Endosc 2014, Jun 11 [Epub ahead of print]
Bibliography

Dol http://dx.doi.org/

10.1055/s-0034-1390724

Endoscopy 2015; 47: E22-E23

(c) Georg Thieme Verlag KG

Stuttgart · New York

ISSN 0013-726X

\section{Corresponding author}

Jérémie Jacques, MD

Service d'Hépato-gastro-entérologie CHU Dupuytren 87042

Limoges

France

Fax: +33-5-55058733

jeremiejacques@gmail.com 